\title{
Pengetahuan Masyarakat dan Pelaksanaan Wawancara Program Indonesia Sehat dengan Pendekatan Keluarga (PIS-PK) di Beberapa Puskesmas di Indonesia
}

\author{
Knowledge of Community and Conducting Interviews the Healthy Indonesia \\ Program with a Family Approach (PIS-PK) in Several Primary of Health \\ Care in Indonesia
}

Made Ayu Lely Suratri ${ }^{1}$, Tince Arniati Jovina ${ }^{1}$, dan Eva Sulistyowati ${ }^{1}$
1) Pusat Penelitian dan Pengembangan Sumber Daya dan Pelayanan Kesehatan, Jalan Percetakan Negara No. 29 Jakarta
10560, Indonesia
Korespondensi: made.lely@gmail.com

Submitted: 8 Februari 2019, Revised: 25 Maret 2019, Accepted: 9 April 2019

https://doi.org/10.22435/jpppk.v3i1.1867

\begin{abstract}
Abstrak
Program Indonesia Sehat dengan Pendekatan Keluarga (PIS-PK) merupakan kegiatan kunjungan rumah yang bertujuan untuk meningkatkan akses keluarga terhadap pelayanan kesehatan yang komprehensif, mendukung tercapainya Standar Pelayanan Minimal (SPM), dan JKN dalam rangka mewujudkan Indonesia sehat. Program ini dilaksanakan di seluruh puskesmas di Indonesia secara bertahap sejak tahun 2016. Puskesmas sesuai dengan mandatory dari Permenkes No. 75 tahun 2014 melaksanakan kunjungan rumah dalam rangka meningkatkan jangkauan sasaran dan mendekatkan akses pelayanan kesehatan. Kegiatan kunjungan dilakukan dengan mengintegrasikan kegiatan UKP dan UKM secara berkesinambungan berdasarkan data pada profil keluarga. Tujuan penelitian untuk memperoleh gambaran pengetahuan dan pelaksanaan kunjungan rumah PIS-PK di beberapa puskesmas di Indonesia. Metode penelitian adalah riset operasional dengan pendekatan Participatory Action Research (PAR), merupakan bagian Riset Implementasi PIS-PK yang dilaksanakan oleh Puslitbang Sumber Daya dan Pelayanan Kesehatan tahun 2018. Penelitian ini dilakukan pada tahun 2018 di beberapa puskesmas di empat provinsi terpilih yaitu Lampung, Jawa Tengah, NTT, dan Kalimantan Selatan. Populasi penelitian adalah 10 rumah tangga terpilih di wilayah puskesmas yang telah dikunjungi oleh petugas puskesmas. Total rumah tangga yang dijadikan sampel penelitian sebanyak 80 rumah tangga. Wawancara dengan menggunakan instrumen berupa kuesioner validasi dan Prokesga yang digunakan oleh petugas puskesmas. Hasil validasi data menunjukkan bahwa belum semua puskesmas melakukan sosialisasi kepada masyarakat tentang pelaksanaan kunjungan rumah dalam rangka PIS-PK. Petugas yang melakukan kunjungan rumah tidak menanyakan keseluruhan pertanyaan Prokesga dan pengukuran tekanan darah. Senada dengan hal tersebut, hampir sebagian besar responden belum mengetahui atau mendengar tentang PIS-PK. Sebagian besar puskesmas belum melakukan kunjungan ulang bila anggota rumah tangga (ART) tidak ada dirumah.
\end{abstract}

Kata kunci: validasi data, PIS-PK, Puskesmas

\section{Abstract}

The Healthy Indonesia Program with a Family Approach (PIS-PK) is a home visit activity that aims to increase family access to comprehensive health services, support the achievement of Minimum Service Standards (SPM), and JKN in order to realize a healthy Indonesia. The program was implemented in all health centers in Indonesia, gradually starting in 2016. The the Primary of Health Care in accordance with the mandatory of Permenkes No. 75 of 2014 carried out home visits in order to increase the reach of targets and bring 
access to health services closer. Visiting activities are carried out by integrating UKP and UKM activities on an ongoing basis based on data on family profiles. The purpose of this study was to obtain an overview of the knowledge and implementation of PIS-PK home visits in several health centers in Indonesia. The method of this research is operational research using the Participatory Action Resarch (PAR) approach, which is part of the PIS-PK Implementation Research carried out by the Research and Development Center for Resources and Health Services in 2018. This research was conducted in 2018 in several Primary of Health Care in four selected provinces, that is Lampung, Central Java, NTT, and South Kalimantan. The study population was 10 selected households in the Primary of Health Care area that had been visited by the Primary of Health Care officers. The total number of households used as research samples was 80 households. Interviews using the instrument were in the form of validation questionnaires and health programs that were used by the Primary of Health Care officers. The results of data validation show that not all the Primary of Health Care have provided information to the public about the implementation of home visits within the framework of the PIS-PK. The staff who made a home visit did not ask about the overall health questions and blood pressure measurements. In line with this, almost the majority of respondents did not know or hear about PIS-PK. Most public health centers haven't been re-visited if there weren't its members.

Keywords: data validation, PIS-PK, Primary of Health Care

\section{Pendahuluan}

Program Indonesia Sehat merupakan program utama pembangunan kesehatan yang kemudian direncanakan pencapaiannya melalui Rencana Strategis Kementerian Kesehatan Tahun 2015-2019, melalui ketetapan Keputusan Menteri Kesehatan RI Nomor HK.02.02/Menkes/52/2015. Sasaran dari Program Indonesia Sehat adalah meningkatnya derajat kesehatan dan status gizi masyarakat melalui upaya kesehatan dan pemberdayaan masyarakat yang didukung dengan perlindungan finansial dan pemerataan pelayanan kesehatan. Pelaksanaan Program Indonesia Sehat diperlukan pendekatan keluarga, yang mengintegrasikan Upaya Kesehatan Perorangan (UKP) dan Upaya Kesehatan Masyarakat (UKM) secara berkesinambungan, dengan target keluarga, berdasarkan data dan informasi dari Profil Kesehatan Keluarga. Menteri Kesehatan telah menetapkan Peraturan Menteri Kesehatan (Permenkes) Nomor 39 Tahun 2016 tentang Penyelenggaraan Program Indonesia Sehat dengan Pendekatan Keluarga (PISPK). ${ }^{1}$

Tujuan dari PIS-PK adalah untuk meningkatkan akses keluarga berserta anggotanya terhadap pelayanan kesehatan yang komprehensif, meliputi pelayanan promotif dan preventif serta pelayanan kuratif dan rehabilitatif dasar; mendukung pencapaian standar pelayanan minimal kabupaten/kota; melalui peningkatan akses dan skrining kesehatan; mendukung pelaksanaan jaminan kesehatan nasional dengan meningkatkan kesadaran masyarakat untuk menjadi peserta Jaminan Kesehatan Nasional; dan mendukung tercapainya tujuan Program Indonesia Sehat dalam rencana strategis Kementerian Kesehatan Tahun 2015-2019. ${ }^{1}$

Dalam rangka pelaksanaaan PIS-PK telah disusun 12 indikator utama yang terdiri dari: 1) keluarga mengikuti program Keluarga Berencana (KB); 2) ibu melakukan persalinan di fasilitas kesehatan; 3) bayi mendapat imunisasi dasar lengkap; 4) bayi mendapat air susu ibu (ASI) eksklusif; 5) balita mendapatkan pemantauan pertumbuhan; 6) penderita tuberkulosis paru mendapatkan pengobatan sesuai standar; 7) penderita hipertensi berobat secara teratur; 8) penderita gangguan jiwa mendapatkan pengobatan dan tidak ditelantarkan; 9) anggota keluarga tidak ada yang merokok; 10) keluarga sudah menjadi anggota Jaminan Kesehatan Nasional (JKN); 11) keluarga mempunyai akses sarana air bersih; dan 12) keluarga mempunyai akses atau menggunakan jamban sehat. Keluarga merupakan fokus dalam pelaksanaan program Indonesia Sehat dengan pendekatan keluarga. ${ }^{1,2}$

Puskesmas merupakan fasilitas pelayanan kesehatan menyelenggarakan upaya kesehatan masyarakat dan upaya kesehatan perseorangan tingkat pertama, dengan lebih mengutamakan upaya promotif dan preventif, untuk mencapai derajat kesehatan masyarakat yang setinggi-tingginya di wilayah kerjanya. Pendekatan keluarga adalah salah satu cara Puskesmas untuk meningkatkan jangkauan 
sasaran dan mendekatkan/meningkatkan akses pelayanan kesehatan di wilayah kerjanya dengan mendatangi keluarga.

Hasil evaluasi sementara PIS-PK di 8 provinsi yang dilaksanakan oleh Puslitbang UKM Badan Litbangkes pada tahun 2016, secara umum menunjukkan bahwa hanya beberapa kabupaten saja yang telah mulai melakukan persiapan dan pendataan awal. Kendala puskesmas belum melakukan pendataan adalah : 1) Program Keluarga Sehat belum menjadi prioritas, 2) Program Keluarga Sehat belum terinformasikan kepada Kepala Dinas Kabupaten walaupun stafnya merasa telah melaporkan hasil pertemuan sosialisasi di Kemenkes, 3) Belum cairnya dana akibat belum disahkannya anggaran perubahan, 4) Merasa dana yang 50 juta tidak mungkin cukup untuk melakukan pendataan mengingat jumlah penduduk yang banyak dan keterbatasan SDM yang ada di puskesmas (Puslitbang UKM, 2016). ${ }^{3}$

Hasil riset Implementasi PIS-PK yang dilaksanakan di Kabupaten Lampung Selatan pada tahun 2017 juga menunjukkan hasil yang sama, namun kendala tersebut dapat diminimalisir dengan adanya komitmen bersama antara pemerintah daerah, dinas kesehatan, puskesmas dan masyarakat. ${ }^{4}$ Terbatasnya jumlah surveyor dapat di atasi dengan On Job Training (OJT) dan kerja sama dengan perguruan tinggi/Poltekkes setempat. Dinas Kesehatan Provinsi Lampung yang mengadakan Memorandum of Understanding (MoU) dengan Universitas Malahayati dan Poltekkes untuk mahasiswa yang melaksanakan PKL akan memiliki desa binaan termasuk dalam melaksanakan PIS-PK. ${ }^{4}$

Implementasi pelaksanaan PIS-PK oleh puskesmas akan berjalan dengan baik, bila terdapat komunikasi yang baik pusat-daerah dan pelaksana, dukungan pemda dan lintas sektor, tersedianya sarana prasarana, anggaran, serta SDM yang cukup. ${ }^{1}$ Puskesmas mempunyai tugas melaksanakan kebijakan kesehatan untuk mencapai tujuan pembangunan kesehatan di wilayah kerjanya dalam rangka mendukung terwujudnya kecamatan sehat. Berdasarkan prinsip paradigma sehat puskesmas mendorong seluruh pemangku kepentingan untuk berkomitmen dalam upaya mencegah dan mengurangi resiko kesehatan yang dihadapi individu, keluarga, kelompok dan masyarakat, dan berdasarkan prinsip pertanggungjawaban wilayah puskesmas menggerakkan dan bertanggung jawab terhadap pembangunan kesehatan di wilayah kerjanya. ${ }^{5}$ Tujuan dari penelitian ini untuk menggali pengetahuan masyarakat dan pelaksanaan wawancara Program Indonesia Sehat dengan Pendekatan Keluarga di beberapa puskesmas di Indonesia.

\section{Bahan dan Metode}

Penelitian ini merupakan bagian dari riset operasional bersifat pendampingan dengan pendekatan Participatory Action Resarch (PAR) yang dilaksanakan oleh Puslitbang Sumber Daya dan Pelayanan Kesehatan pada tahun 2018. ${ }^{6}$ Penelitian ini dilakukan pada tahun 2018 di lima provinsi terpilih yaitu Provinsi Lampung, Jawa Tengah, NTT, Kalimantan Selatan, dan Sulawesi Tengah, dan di delapan puskesmas yaitu empat puskesmas di Kabupaten Lampung Selatan (Puskesmas Wayurang, Karanganyar, Tanjung Sari dan Tanjung Bintang), Puskesmas Banjarnegara 1 (Kabupaten Banjarnegara, Jawa Tengah), Puskesmas Lahihuruk (Kabupaten Waikabubak, NTT), Puskesmas Giri Mulya (Kabupaten Tanah bumbu, Kalimantan Selatan), dan Puskesmas Tawaeli (Kota Palu, Sulawesi Tengah). Pemilihan lokasi didasarkan adanya Balai/Loka sebagai UPT Badan Litbangkes sehingga memudahkan pendampingan dan koordinasi, dan setelah koordinasi dengan dinas kesehatan dan puskesmas setempat maka terpilih satu desa. Pemilihan Kabupaten Lampung Selatan karena merupakan lanjutan pendampingan PIS-PK di Kabupaten Lampung Selatan, Provinsi Lampung. Validasi dilakukan dengan cara wawancara langsung ke rumah tangga yang sudah dipilih secara sampling untuk melihat pengetahuan masyarakat tentang PIS-PK; pelaksanaan wawancara dan pemeriksaan yang dilakukan oleh petugas puskesmas. Informan adalah individu sasaran wawancara untuk mendapatkan keterangan dan data untuk keperluan penggalian informasi. ${ }^{7}$ Wawancara dengan menggunakan instrumen berupa kuesioner validasi (wawancara mendalam) dan Prokesga serta Pinkesga yang sama digunakan oleh petugas puskesmas. Wawancara mendalam dilakukan kepada 10 informan yang mewakili 10 rumah tangga yang sudah dilakukan kunjungan rumah 
oleh petugas/surveyor puskesmas. Total rumah tangga yang dijadikan sampel penelitian sebanyak 80 rumah tangga. ${ }^{8}$ Pengumpulan informasi pada wawancara mendalam ditanyakan tentang pengetahuan responden tentang keluarga sehat, penjelasan petugas, pertanyaan dan pemeriksaan yang dilakukan oleh petugas serta komponen pertanyaan yang ada pada Prokesga yang meliputi 12 indikator PIS-PK.

Hasil

Kegiatan validasi pelaksanaan PIS-PK di beberapa puskesmas di Indonesia menunjukkan bahwa:

\section{Pengetahuan Masyarakat tentang PIS-PK}

Definisi dan makna keluarga sehat belum semua dipahami oleh warga. Sebagian besar responden di 4 puskesmas di Lampung Selatan, belum tahu apa yang dimaksud dengan PISPK, umumnya hanya mendengar atau berusaha menjawab dengan pengertian masing-masing. Responden yang tahupun ternyata tidak mengetahui maksud dari program keluarga sehat, hanya tahu kalau didatangi petugas dan ditanya-tanya.

"Tidak tau ya ... apa ya...maksudnya itu apa ya Bu... Program Keluarga Sehat?"

“aduh apa ya.. tidak tau ..."(Keluarga A)

"badan sehat, tidak pernah sakit, lingkungan sehat" (Keluarga B)

Informan di Desa Marga Agung, Lampung Selatan pada umumnya tidak mengetahui tujuan kunjungan petugas puskesmas ke rumah tangga. Mereka tidak paham dengan "Keluarga Sehat", tetapi semua menyatakan melihat spot iklan TV mengenai "kunjungan rumah" untuk Keluarga Sehat. Sebagian besar rumah tangga yang diwawancarai tahu tentang keluarga sehat namun tidak mengerti apa itu keluarga sehat.

Namun beberapa masyarakat di Desa Wanakuka, wilayah kerja Puskesmas Lahihuruk, Waikabubak memahami dan dapat memberi contoh maksud kata "sehat " sebagai berikut:

"keluarga yang lingkungannya bersih, punya jamban dan kalau minum pakai air matang" (responden ruta...)

"keluarga yang sehat jasmani dan rohani"

(responden ruta....)

" keluarga yang perhatikan makanan yang dimakan, cara asuh anak seperti antar ke posyandu" (responden ruta...)

"'keluarga yang jaga kebersihan diri dan makan sehat" (responden ruta...)

\section{Sosialisasi Kegiatan PIS-PK}

Sosialisasi PIS-PK dari puskesmas sudah dilaksanakan. Misalnya informan rumah tangga di Kelurahan Argasoka wilayah kerja Puskesmas Banjarnegara 1 menyatakan sudah ada sosialisasi melalui Ketua RT dan juga ke warga secara getok tular, walaupun sebagian informan lainnya menyatakan belum pernah mendapatkan sosialisasi dari petugas puskesmas.

Sebagian informan di 4 desa di wilayah Lampung Selatan menjawab bahwa sebelumnya Pak RT memberitahukan akan ada petugas yang datang dan diminta menyiapkan fotocopy KK. Seluruh responden menyatakan bahwa ada petugas yang datang ke rumah sehubungan dengan program keluarga sehat. Informan di Desa Marga Agung Lampung Selatan menyatakan bahwa sosialisasi sebagian besar melalui Kepala Dusun, lewat pengajian ataupun pengumuman di masjid sekitar.

Sebagian responden menjawab pernah ada sosialisasi dari Kepala Dusun, hampir seluruh responden mengatakan bahwa ada petugas yang datang ke rumah sehubungan dengan program keluarga sehat, biasanya 2 orang.

"Ada, dari kadus... 1 minggu ini" (Keluarga A) "petugas yang datang 2 orang, sebelum puasa" (Keluarga C)

\section{Pelaksanaan Kunjungan Rumah oleh Petugas Puskesmas}

\section{a. Wawancara Prokesga (Profil Kesehatan Keluarga)}

Pertanyaan-pertanyaan yang mencakup 12 indikator Keluarga Sehat, menurut seluruh informan di Desa Argasoka, sudah ditanyakan oleh petugas puskesmas sesuai dengan rambu-rambu di setiap pertanyaan. Namun, ada sebagian kecil informan yang menyatakan bahwa pertanyaan tentang ODGJ tidak ditanyakan.

\section{b. Penggunaan PINKESGA dan KIE}

Hampir semua informan menyatakan bahwa petugas puskesmas memberikan informasi terkait dengan permasalahan yang ditemukan di 
masing-masing keluarga dengan menggunakan Paket Informasi Keluarga (PINKESGA), kecuali 1 informan yang menyatakan tetap diberikan informasi (KIE) namun tidak menggunakan PINKESGA karena menurut petugas puskesmas pada saat itu PINKESGA habis. Sebagian kecil informan mengatakan bahwa petugas memberikan informasi atau penyuluhan dari seluruh paket PINKESGA, tidak difokuskan hanya pada permasalahan kesehatan yang ditemui di keluarga tersebut saja. PINKESGA diadakah oleh puskesmas dengan dana BOK. Dinas Kesehatan Kabupaten Banjarnegara juga mempunyai PINKESGA untuk dibagikan ke puskesmas, namun tidak sejumlah yang dibutuhkan oleh puskesmas. Hasil penelitian menunjukkan bahwa sebagian besar informan diragukan mengetahui Rumah Desa Sehat, namun sebagian informan tidak tahu apakah di wilayah tersebut terdapat Rumah Desa Sehat. Menurut informan, yang dimaksud dengan Rumah Desa Sehat hampir sama dengan definisi Keluarga Sehat yaitu lingkungan bersih, makan makanan bergizi, ada jamban, ada ventilasi, tidak kumuh, ada air bersih, sampah dikelola dengan baik, dan ada pepohonan di depan atau di sekitar rumah. Peran Rumah Desa Sehat adalah agar lingkungan sehat, bisa menjadi tempat Posyandu, dan bisa menjadi contoh rumah sehat. Tentang Kampung KB, hampir semua informan mengaku tidak tahu tentang Kampung KB. Hanya dua orang informan yang menyatakan tahu tentang Kampung KB dan mendefinisikannya sebagai kampung dengan keluarga-keluarga yang mengikuti KB.

\section{c. Pemeriksaan Tekanan Darah}

Sebagian kecil informan juga menyatakan bahwa petugas puskesmas tidak melakukan pengukuran tekanan darah dengan alasan petugas tidak membawa tensimeter. Beberapa informan menyatakan bahwa petugas puskesmas hanya mewawancarai anggota rumah tangga yang ditemui saat itu dan belum melakukan kunjungan ulang bagi anggota rumah tangga (ART) yang belum diwawancarai.

\section{d. Kunjungan ulang}

Informan di Desa Wanukaka, Waikabubak, menyatakan bahwa tidak semua ART diwawancara dan tidak ada perjanjian waktu untuk kunjungan ulang, tidak ada penanda untuk rumah yang telah dikunjungi sehingga ada kemungkinan beberapa kali dikunjungi oleh tim.

Informan di Desa Marga Agung, Lampung Selatan menyatakan bahwa tidak seluruh anggota rumah tangga diwawancarai oleh petugas puskesmas. Rata- rata hanya diwawancarai 1 orang per rumah tangga (ruta). Anggota rumah tangga yang diwawancarai hanya yang berada di rumah sewaktu petugas datang. Sedangkan anggota rumah tangga yang sedang tidak ada di rumah tidak dilakukan kunjungan ulang. Hal ini dikarenakan pemberitahuan dari bidan desa, bahwa pada waktu pendataan minimal ada 1 ART yang ada di rumah. Untuk kunjungan ulang sebagian besar ART menjawab tidak diinformasikan, sedangkan menurut Penanggung Jawab puskesmas, kunjungan ulang semuanya akan dilakukan oleh bidan desa setempat. Sebagian besar rumah tangga ditanyai tentang KB, namun ada 1 ruta yang tidak ditanyai. Surveyor sudah dapat menanyakan kuesioner sesuai dengan kelompok umur.

Sebagian besar surveyor menanyakan masalah penyakit TB, hanya 2 ruta yang tidak ditanyai tentang penyakit tersebut. Pada pengukuran tekanan darah, hampir seluruh anggota rumah tangga yang ada pada saat diwawancarai dilakukan pengukuran darah, hanya ada 2 orang yang tidak dilakukan pengukuran karena surveyor terburu-buru dan anak responden sedang menangis. Hasil pengukuran tekanan darah sebagian besar diberitahukan kepada responden.

Petugas melakukan observasi langsung untuk menilai indikator ketersediaan sumber air bersih dan jamban sehat, baik ke sumur yang digunakan maupun keadaan jamban. Perilaku penggunaan air bersih dan kebiasaan $\mathrm{BAB}$ juga ditanyakan kepada responden. Bila terdapat masalah kesehatan, petugas puskesmas langsung memberikan penyuluhan, namun hanya berupa informasi lisan, PINKESGA sebagai media KIE belum dimanfaatkan optimal meskipun tersedia.

Informan di Lampung Selatan menyatakan bahwa beberapa pertanyaan yang harusnya ditanyakan kepada masing-masing ART eligible ada yang tidak ditanyakan, misalnya pertanyaan tentang apakah ada ART yang mengalami gangguan jiwa berat (ODGJ) dimana sebagain besar keluarga tidak ditanyakan tentang ODGJ, observasi jamban 
sebagian besar tidak diobservasi kondisinya.

"Ditanya ada ngga jambannya? Belum ada.... numpang sama ibu di sebelah, tapi gakdilihat" (ART)

Hampir seluruh responden dilakukan pemeriksaan tekanan darah walaupun tidak semua ART (hanya yang $>15$ tahun yang ditemui), edukasi sebagai intervensi langsung tidak dilakukan, misalnya: keluarga yang eligible tidak ditanya pemberian ASI Eksklusif dan tidak dijelaskan, sebagian besar dari keluarga dengan ART ada yang merokok tidak diberikan penyuluhan tentang rokok dan bahayanya, keluarga yang belum mempunyai JKN tidak diberikan penyuluhan.

Informasi yang menyatakan wawancara mendalam di tingkat rumah tangga dan cek-silang (cross-check) hasil wawancara dengan formulir Prokesga yang telah diisi oleh surveyor. Wawancara dilakukan pada salah satu ART yang dapat dijumpai: pertanyaan tentang ODGJ tidak ditanyakan kepada seluruh keluarga, semua RT dilakukan pemeriksaan tensi darah hipertensi, tetapi tidak pada semua ART. Bila ditemukan kasus diberikan edukasi mengenai cara kontrol tekanan darah (disarankan berobat lanjut ke Puskesmas, serta mengurangi makanan asin). Sebagian besar pertanyaan tentang rokok juga ditanyakan ke ART namun tidak semua diedukasi, separuh ruta ditanyakan petugas mengenai ketersediaan air bersih, namun sebagian besar petugas tidak menanyakan sumber air terlindung dan tidak dijelaskan oleh petugas mengenai pentingnya sumber air terlindung. PINKESGA hanya ditunjukkan pada 2 ruta saat pengumpulan data, sehingga informasi mengenai perilaku ART yang menjadi indikator KS tidak dapat diperoleh secara lengkap. Hasil wawancara mendalam dari keluarga yang dikunjungi, sebagian besar pertanyaan Prokesga ditanyakan sesuai kondisi responden.

\section{Pembahasan}

Hasil validasi data PIS-PK di 8 desa di wilayah kerja puskesmas di lima provinsi diketahui bahwa pengetahuan informan tentang PIS-PK masih kurang. Penjelasan yang diberikan oleh petugas puskesmas belum mampu memberikan tambahan pengetahuan tentang program keluarga sehat. Seluruh informan belum mengetahui tentang Rumah Desa Sehat dan Kampung KB. Namun demikian beberapa informan mengetahui dari spot TV. Perlu sosialisasi yang bersifat ringan yang lebih intensif misalnya melalui media sosial, radio, televisi. Pengetahuan adalah berbagai gejala yang ditemui dan diperoleh manusia melalui pengamatan indra. ${ }^{9}$ Pengindraan tersebut melalui panca indra manusia yaitu penglihatan, pendengaran, penciuman, rasa dan raba dengan sendiri ${ }^{10}$, sedangkan menurut Hidayat (2007), pengetahuan (Knowledge) adalah suatu proses dengan menggunakan pancaindra yang dilakukan seseorang terhadap objek tertentu dapat menghasilkan pengetahuan dan keterampilan. Pengetahuan seseorang biasanya diperoleh dari pengalaman yang berasal dari berbagai macam sumber seperti, media poster, kerabat dekat, media massa, media elektronik, buku petunjuk, petugas kesehatan, dan sebagainya. ${ }^{11}$ Menurut Notoatmodjo $(2010)^{12}$, pengetahuan merupakan domain yang sangat penting dalam membentuk perilaku atau tindakan seseorang. Perilaku yang didasari oleh pengetahuan akan lebih langeng daripada perilaku yang tidak didasari oleh pengetahuan.

Sosialisasi ke masyarakat sudah dilakukan baik secara formal maupun informal yang melibatkan lintas sektor melalui pertemuan lokakarya mini, media sosial, bidan desa dan pertemuan desa. Lintas sektor sudah berperan dalam memberikan listing nama KK, mengkondisikan warganya sehingga kunjungan rumah ulang tidak sampai berkali-kali dilakukan. Pelaksanaan kunjungan rumah juga sudah berjalan dengan lancar minim penolakan dari masyarakat karena adanya dukungan dari kader, RT/RW, Toma dan aparat desa setempat. Intervensi langsung dengan memberikan edukasi maupun rujukan kepada keluarga bermasalah kesehatan yang masih belum maksimal juga perlu lebih ditingkatkan agar masyarakat benar-benar merasakan kehadiran puskesmas di setiap keluarga, mendekatkan akses terhadap fasilitas kesehatan. Sesuai dengan Permenkes No 39 Tahun 2016 dalam tahap persiapan pelaksanaan PIS-PK (P1), harus dilakukan sosialisasi baik internal kepada petugas puskesmas yang belum dilatih maupun eksternal yang melibatkan lintas sektor di wilayah kerja puskesmas. Sosialisasi yang baik dan berhasil akan sangat membantu pelaksaan PIS-PK di lapangan. ${ }^{2}$

Pelaksanaan kunjungan rumah oleh petugas puskesmas belum dilakukan secara optimal. Sebagian besar petugas sudah menanyakan 
pertanyaan yang ada di Prokesga kepada ART, sesuai dengan kategori umur, kecuali pertanyaan mengenai indikator ODGJ. Karena merupakan pertanyaan sensitif, misalnya apakah ada anggota rumah tangga yang mengalami gangguan jiwa ini jarang ditanyakan, dan keberadaan ODGJ yang sering disembunyikan oleh keluarganya tidak akan tergali/ terdeteksi bila pertanyaan tersebut tidak ditanyakan. Berdasarkan kesepakatan, pertanyaan ini akan ditanyakan kepada ketua RT mengenai adanya ODGJ di sekitar lingkungan, dan tidak ditanyakan langsung di tingkat rumah tangga. Data ODGJ pada Riskesdas 2018 berupa prevalensi (permil) Rumah Tangga dengan ART Gangguan Jiwa Skizofrenia/ Psikosis adalah 6,7. ${ }^{13}$

Observasi jamban dan Sarana Air Bersih (SAB) sudah dilakukan sesuai dengan petunjuk dalam buku ajar untuk memastikan kepemilikan dan jenisnya, sehingga sebagian besar petugas sudah melakukan pengukuran tekanan darah, tapi hanya dilakukan pada ART yang ada saat wawancara. Pemeriksaan tekanan darah sebenarnya merupakan nilai tambah tersendiri dalam pelaksaan PIS-PK, masyarakat lebih senang dan antusias bila ikut diperiksa tekanan darah dibandingkan bila hanya wawancara saja. Penggunaan PINKESGA belum dimaksimalkan, jika ada ditemukan masalah kesehatan pada saat kunjungan ada yang belum dilakukan intervensi penyuluhan seharusnya bisa langsung Perlu selalu dilakukan refresh/mengulang pembelajaran yang sudah diterima, membuka kembali buku ajar PIS-PK dan memahami definisi operasional masing-masing indikator. Seperti hanya pada saat pendampingan, tim peneliti melakukan refreshing secara rutin bersama petugas puskesmas dengan dikawal penuh kepala puskesmas. $^{8}$ Penggunaan Pinkesga terlihat belum optimal. Bila ditemukan permasalahan kesehatan dalam keluarga harus dilakukan edukasi. Petugas sejak pelatihan sudah diberikan Pinkesga untuk 12 indikator PISPK yang berguna sebagai media edukasi keluarga. Selain itu, temuan lain diluar 12 indikatorpun harus dicatat, diberikan intervensi lanjutan serta dilaporkan kepada pemegang program terkait tindak lanjutnya. Pandangan petugas diharapkan kegiatan PIS-PK bukan hanya sebagai pendataan. Misalnya: ketika kunjungan rumah ditemukan ART yang terdiagnosis TB maka petugas harus menyampaikan edukasi terkait TB kepada penderita dan seluruh anggota keluarganya, meminta agar ART lainnya memeriksakan diri ke puskesmas dan melaporkan hasil temuan kepada pemegang program TB untuk selanjutnya diperiksa kontak penderita tersebut.

Kunjungan ulang belum dilaksanakan secara maksimal oleh hampir sebagian besar petugas puskesmas. Rata-rata petugas hanya mendata ART yang ada di rumah saat pendataan. Hal ini mengingat keterbatasan jumlah SDM puskesmas dan waktu kunjungan/jam kerja yang dilakukan. Perlu kerjasama antara petugas puskesmas dengan kader/bidan desa setempat agar dapat dilakukan kunjungan ulang sehingga seluruh ART dapat di data.

Peran lintas sektor terkait dalam mensukseskan PIS-PK terbungkus dalam Germas (Gerakan Masyarakat Hidup Sehat) dituangkan dalam Instruksi Presiden No. 1 Tahun 2017 bertujuan untuk mempercepat dan mensinergikan tindakan dari upaya promotif dan preventif hidup sehat guna meningkatkan produktivitas penduduk dan menurunkan beban pembiayaan pelayanan kesehatan akibat penyakit. Germas dilakukan melalui peningkatan aktivitas fisik, peningkatan perilaku hidup sehat, penyediaan pangan dan percepatan perbaikan gizi, peningkatan pencegahan dan deteksi dini penyakit, peningkatan kualitas lingkungan, serta peningkatan edukasi hidup sehat. ${ }^{14}$

\section{Kesimpulan}

Pengetahuan informan tentang PIS-PK masih kurang walaupun sosialisasi ke masyarakat sudah dilakukan baik secara formal maupun informal. Pelaksanaan kunjungan rumah dan penggunaan PINKESGA oleh petugas puskesmas belum optimal. Kunjungan ulang belum dilaksanakan secara maksimal.

\section{Saran}

Sosialisasi PIS-PK perlu dilakukan secara kontinyu agar masyarakat makin banyak yang tahu tentang tujuan dari program ini. Kunjungan rumah yang dilakukan petugas perlu ditingkatkan kualitasnya sesuai dengan DO (Definisi Operasional) yang benar. Masih perlu meningkatkan peran lintas sektor. 


\section{Ucapan Terima Kasih}

Penulis mengucapkan terima kasih kepada Kepala Puslitbang Sumber Daya dan Pelayanan Kesehatan, Badan Litbangkes, Kementerian Kesehatan RI yang telah memberikan izin untuk membuat artikel tentang "Pengetahuan Masyarakat dan Pelaksanaan Wawancara Program Indonesia Sehat dengan Pendekatan Keluarga (PIS-PK) di Beberapa Puskesmas di Indonesia" menggunakan data Hasil Penelitian Riset Implementasi Peraturan Menteri Kesehatan RI No. 39 Tahun 2016 tentang Program Indonesia Sehat dengan Pendekatan Keluarga di Beberapa Puskesmas di Indonesia Tahun 2018.

\section{Daftar Rujukan}

1. Kementerian Kesehatan RI. Pedoman Umum Program Indonesia Sehat dengan Pendekatan Keluarga, Edisi-2. 2017.

2. Kementerian Kesehatan RI, Peraturan Menteri Kesehatan Nomor 39 Tahun 2016 tentang Pedoman Penyelenggaraan Program Indonesia Sehat dengan Pendekatan Keluarga. 2016.

3. Irianto J. dkk. Evaluasi PIS-PK Tahun 2016. Puslitbang Upaya Kesehatan Masyarakat. Badan Litbang Kesehatan. 2017.

4. Sulistiowati, E. Riset Implementasi PISPK di Kabupaten Lampung Selatan Provinsi Lampung. Puslitbang Sumber Daya dan Pelayanan Kesehatan. Badan Litbangkes. Laporan Penelitian. 2017.
5. Kementerian Kesehatan RI. Peraturan Menteri Kesehatan No. 75 Tahun 2017 tentang Pusat Kesehatan Masyarakat. Petunjuk Teknis Penguatan Manajemen Puskesmas dengan Pendekatan Keluarga. Edisi-2. 2017.

6. Satori, Djam'an dan Komariah A. Metodologi Penelitian Kualitatif. Bandung: Alfabeta. 2012.

7. Priadana, Sidik M dan Muis S. Metodologi Penelitian Ekonomi \& Bisnis. Yogyakarta: Graha Ilmu. 2009.

8. Sulistiowati E dkk. Riset Implementasi Peraturan Menteri Kesehatan RI No. 39 Tahun 2016 tentang Program Indonesia Sehat dengan Pendekatan Keluarga (PIS-PK) di Beberapa Puskesmas di Indonesia. Puslitbang Sumber Daya dan Pelayanan Kesehatan. Badan Litbangkes. 2018.

9. Mahmud, Psikologi Pendidikan. CV Mustika Setia, Bandung. 2010: Hlm. 169.

10. Wawan A dan Dewi M. Teori dan Pengukuran Pengetahuan Sikap, dan Perilaku Manusia. Nuha Medika, Yogyakarta. 2011: Hal. 11.

11. Hidayat. Statistik Kesehatan. Rajawali Pers. Jakarta. 2010.

12. Notoatmodjo S. Ilmu Perilaku Kesehatan. Jakarta: Rineka Cipta. 2010.

13. Kementerian Kesehatan RI. Laporang Nasional Riskesdas 2018. Lembaga Penerbit Badan Litbangkes.(LPB). 2019: Hal. 223-233.

14. Instruksi Presiden RI No.1 Tahun 2017 tentang Gerakan Masyarakat Hidup Sehat. 2017. 